
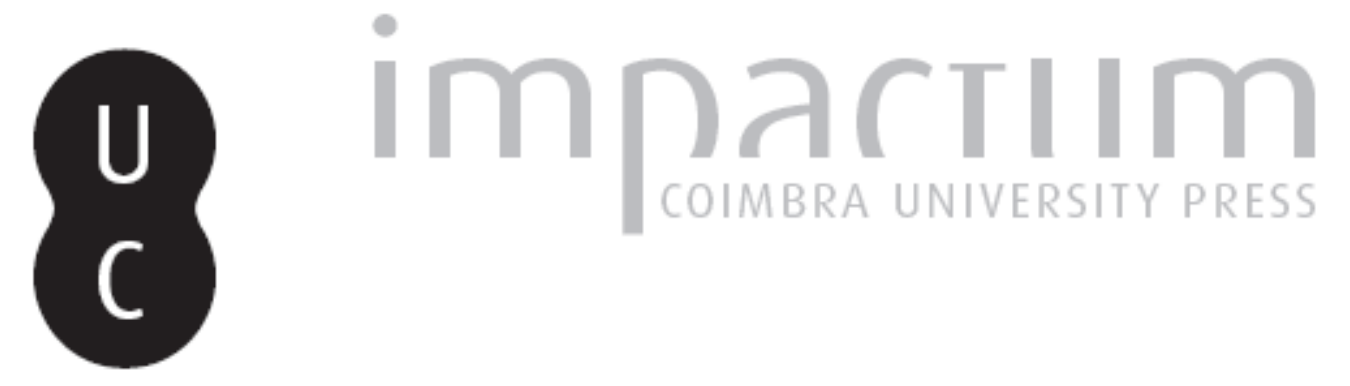

\title{
[Recensão a] Huffstot, Maria da Luz de G. Velloso da Costa - As origens do Cristianismo na Lusitânia
}

\author{
Autor(es): $\quad$ Martins, Armando
}

Publicado por: Centro de História da Universidade de Lisboa

URL persistente:

URI:http://hdl.handle.net/10316.2/23941

DOI:

DOI:http://dx.doi.org/10.14195/0871-9527_18_27

Accessed : $\quad$ 26-Apr-2023 16:15:59

A navegação consulta e descarregamento dos títulos inseridos nas Bibliotecas Digitais UC Digitalis, UC Pombalina e UC Impactum, pressupõem a aceitação plena e sem reservas dos Termos e Condições de Uso destas Bibliotecas Digitais, disponíveis em https://digitalis.uc.pt/pt-pt/termos.

Conforme exposto nos referidos Termos e Condições de Uso, o descarregamento de títulos de acesso restrito requer uma licença válida de autorização devendo o utilizador aceder ao(s) documento(s) a partir de um endereço de IP da instituição detentora da supramencionada licença.

Ao utilizador é apenas permitido o descarregamento para uso pessoal, pelo que o emprego do(s) título(s) descarregado(s) para outro fim, designadamente comercial, carece de autorização do respetivo autor ou editor da obra.

Na medida em que todas as obras da UC Digitalis se encontram protegidas pelo Código do Direito de Autor e Direitos Conexos e demais legislação aplicável, toda a cópia, parcial ou total, deste documento, nos casos em que é legalmente admitida, deverá conter ou fazer-se acompanhar por este aviso.

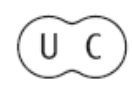



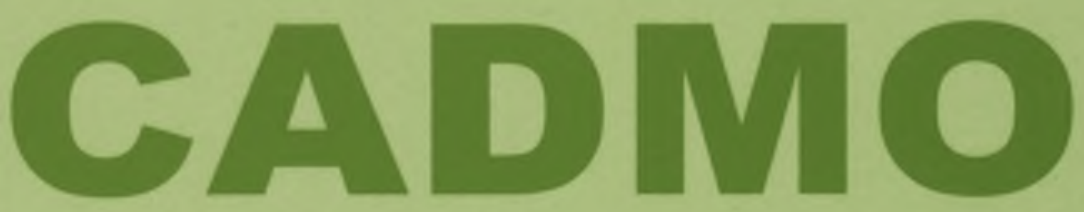

Revista de História Antiga

\author{
Centro de História \\ da Universidade de Lisboa
}

18

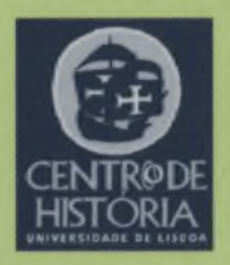

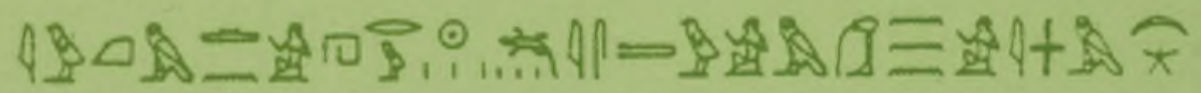

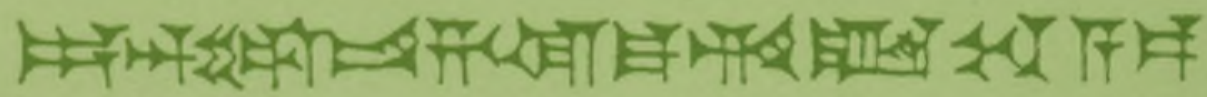

MHNIN AEI $\Delta$ E $\Theta E A ~ \Pi H \Lambda H I A \triangle E \Omega$ 
O cotejo da leitura do livro de M. S. C. com os objectivos enunciados na sua introdução permite constatar que a autora cumpre plenamente as suas intenções, contribuindo, deste modo, não só para a formação de um corpus bibliográfico atractivo e de qualidade sobre as relações da Antiguidade Clássica e cinema, mas também para a sedimentação da ideia de que a cultura e a história clássicas auferem de um enorme potencial no desenho de temas contemporâneos tão controversos como os da religião, sexualidade, sociedade e política.

\section{Cláudia Teixeira}

MARIA DA LUZ DE G. VELLOSO DA COSTA HUFFSTOT, As Origens do Cristianismo na Lusitânia. Lisboa, Universidade Lusíada Editora, 2008, 178 pp., ISBN 972-8883-41-2.

A Autora (n. no Porto, 1961), actualmente professora na Universidade Lusíada de Lisboa, apresenta-nos, como resultado de cinco anos de investigação, a sua tese de doutoramento, dirigida pelo Doutor Luís García Moreno, da Universidade de Alcalá de Henares (Espanha), apresentada a júri em Janeiro de 2003. O doutoramento na Universidade Lusíada (Lisboa) foi feito no âmbito de História Medieval (Antiguidade Tardia).

O livro, após uma introdução geral (pp. 17-21), encontra-se dividido em três capítulos: I - Fontes escritas e arqueológicas (pp. 23-77); II - Génese do Cristianismo na Lusitânia (pp. 79-111); III - Ortodoxia versus Heterodoxia na Lusitânia (pp. 113-153). Termina com uma conclusão geral (pp. 155-161) e bibliografia, subdividida em fontes (pp. 165-166) e estudos (pp. 167-178). Cada capítulo abre com uma pequena introdução onde se expõe o seu objectivo e encerra com uma conclusão onde se resumem os principais aspectos estudados. A temática global escolhida "procura reconstituir o processo de cristianização desde a sua origem, na província mais ocidental do Império Romano" (p. 17).

$\mathrm{Na}$ introdução geral enunciam-se os vários problemas adiante retomados e debatidos, estabelece-se a cronologia, enumeram-se as fontes, indica-se o método e define-se o objecto.

Precisam-se os limites da Lusitânia nas divisões da Hispânia feitas por Augusto nos anos 27 a. C. e c. de 15 a. C. que, apesar de pequenas variações, iriam manter-se ao longo do Alto Império e não 
seriam afectadas na reorganização de Diocleciano, no final do século III. Tendo a ocupação romana encontrado esta região, etnicamente diferenciada, com nítida fronteira no Tejo e grande disparidade entre o interior e o litoral, o processo de aculturação teria sido fácil junto ao mar e nos vales férteis da Estremadura e Beira Litoral, bem como nas áreas de influência das cidades fluviais, Myrtilis, Emerita Augusta, Salacia e Scallabis, para depois concluir que foi nestas áreas mais romanizadas que se iniciou a cristianização. Mas, falta uma mapa adequadamente estabelecido, onde pudéssemos visualizar e localizar tudo isso com clareza.

A Autora informa-nos que as origens cristãs da Lusitânia foram o resultado das disparidades étnicas e geográficas, tendo tudo começado pelas cidades onde (primeiro factor) as comunidades judaicas teriam atraído os mais antigos missionários cristãos. Esta afirmação que nos traz deixa, desde logo, alguma dúvida, visto que, desde os anos $60-70$, se vinha acentuando o clima de animosidade e ruptura entre judaísmo e cristianismo, na Palestina e nas várias comunidades da Diáspora. O segundo factor da expansão teria sido o comércio com Roma, Cartago e os grandes portos orientais, sendo o terceiro o exército, que veio a tornar-se o pólo unificador dos diferentes povos. Ao exército, diz, se teria ficado a dever a propagação do cristianismo, o que aconteceu «devido a ter utilizado uma religião de carácter salvífico e universalista» (p. 19). O exército estacionado na Lusitânia seria mais uma força de controle da exploração mineira do que uma tropa de ocupação, visto não existir o perigo de grandes sublevações na província. Ora, havendo uma grande proximidade entre este corpo militar e o Norte de África, pode colocar-se a hipótese de o cristianismo da Lusitânia ser originário desse continente. Hipótese que, de facto, é discutida mais adiante.

A cronologia é bem definida: séculos I-V: [O cristianismo] "deve ter sido introduzido, no entanto, no século l» (p. 20) mas é possível que a cristianização a norte do Tejo, no vale do Douro, tenha sido iniciada apenas no final do século IV (p. 155).

Sendo escassas as fontes históricas para o estudo destes aspectos, a Autora refere que utilizou, especialmente, fontes escritas: textos de Ireneu de Lyon e de Tertuliano de Cartago, uma carta sinodal de Cipriano e dos bispos da sua província, actas do concílio de lliberris, actas de mártires, poemas de Prudêncio, escritos hagiográficos anónimos do início do século VII, bem como um conjunto de textos respeitante aos dois movimentos religiosos que nestes séculos 
afligiram a Lusitânia: as heresias do arianismo e do movimento ascético do priscilianismo.

São também utilizadas fontes arqueológicas, monumentais e epigráficas dos séculos IV e V, particularmente abundantes para as cidades, cujo conhecimento vem até às mais recentes escavações de fins do século $X X$.

A concluir a introdução, precisa-se o objectivo: havendo até agora sobre este tema apenas estudos esparsos, reúne-se toda a informação disponivel, para se ter uma visão global e determinar a entrada do cristianismo nesta província bem como «a ascensão e difusão desta religião que caracteriza o Baixo Império" (p. 21). Melhor seria dizer a Antiguidade Tardia e melhor seria prometer (e conseguir) trazer alguma novidade, como sempre se espera de uma dissertação deste tipo.

O primeiro capítulo é dedicado à exposição das fontes que irão ser utilizadas e que aqui divide em: narrativas, normativas, hagiográficas (onde se destacam as Passiones) e arqueológicas.

Ao falar das fontes narrativas diz-se que ao adaptar-se às realidades de cada região, mais de que um cristianismo, surgem vários cristianismos, pois o facto de ele não ter cultura própria leva ao processo de aculturação. Na verdade, há que matizar um pouco tal afirmação, pois o cristianismo continua a ser um só mas adquire várias expressões culturais, forma que hoje se expressa melhor com o conceito de inculturação, forjado nos anos trinta do século passado: a fé como gérmen transplantado e que, sem perda de unidade, se desenvolve segundo o génio das várias culturas (Y. Congar, 1975).

É contestável a afirmação de que a heresia montanista, possivelmente, «porque se espalhou por todo o Mediterrâneo, também deve ter alastrado à Península Ibérica» (p. 28). Que provas temos? A Autora não indica nenhuma e, assim, a sua afirmação fica no domínio do gratuito, pois nem mera hipótese constitui, na medida em que nenhum indício the serve de pressuposto.

Entre as fontes narrativas indicadas destacam-se as actas do concílio de lliberris (actual Granada), discutindo-se, mais uma vez, a data da sua realização, mas sem acrescentar nenhuma pista de solução para as dúvidas existentes. Por outro lado, a análise sucinta dos cânones de Elvira (em vez de lliberris, como é já uso dizer-se na historiografia portuguesa), para caracterizar o estado do cristianismo peninsular, não pode omitir o cânone 33 , a mais antiga imposição feita na história do cristianismo sobre o celibato do clero, problemática nova e que não deixará de se acentuar e ganhar importância, nos 
séculos seguintes, em todo o Ocidente. Era importante tê-lo feito, no contexto das exigências do ascetismo, que mais adiante estuda.

No que diz respeito às fontes arqueológicas, faz falta um mapa que mostrasse todas as localidades aqui indicadas; quanto ao mapa das cupae com a sua legenda, inserido na página 87 , é elaboração de outra autora e devia aqui estar devidamente adaptado.

O capítulo II devia ser, pela temática anunciada, o verdadeiro coração da dissertação com alguma novidade em relação aos estudos anteriores. Ora o que nos é dado é mais uma síntese do já conhecido, não se avançando nenhum elemento novo, nem sequer nenhuma nova hipótese interpretativa dos dados conhecidos.

Por outro lado, não nos parece aceitável a afirmação de que "só com S. Agostinho é que se descobre a missão "universal" da igreja e o papel do patriarca do Ocidente como aquele a quem as igrejas ocidentais se têm que identificar». Além da errada grafia, em letra minúscula, do vocábulo "lgreja» (instituição), dizer isso é ignorar a história do primado romano, antes daquela data, em especial a doutrina e acção do papa Dâmaso (366-384), na reivindicação monopolística das prerrogativas da "Sé Apostólica", não fundada por decreto sinodal (como a de Constantinopla), mas pelos dois apóstolos Pedro e Paulo e cujo exercício da potestas se afirmava já na Itália, no Ocidente e no orbis christianus. Em relação à Península Ibérica, sem serem muitos os sinais concretos, não pode ignorar-se a declaração soberana do primado romano do seu sucessor, o papa Sirício (384-399). Não pensamos também que o uso do termo ecclesia tenha causado algum "conflito" em relação ao uso do termo basilica, como é afirmado na p. 91, numa frase cuja sintaxe está muito mal tratada. Impunha-se retirar algumas consequências do uso geograficamente diferenciado daquela terminologia, o que não foi feito.

$\mathrm{Na}$ página 101 teria sido mais clarificador do texto a introdução de mais um mapa, elaborado pela Autora, e que actualizasse o da figura 8 (p. 57), esclarecendo adequadamente, em legenda, as siglas utilizadas.

Na página 110 não se percebe muito bem a que "exageros por parte do papa Clemente I" a Autora se refere. Ainda que duvidosas, deviam ser indicadas as supostas datas de seu pontificado (88?-97?), para melhor nos situarmos. Clemente não diz "com orgulho que a disciplina das legiões romanas se devia à comunidade cristã»! Como estava ela naqueles anos? Leia-se atentamente o capítulo 37 da primeira carta de Clemente aos Coríntios. Ao contrário, este bispo de 
Roma, que se mostrou um notável organizador institucional, é com certo orgulho de ser romano que propõe, como modelo, para a comunidade cristã nascente, a disciplina admirável da legião: a hierarquia, a obediência aos chefes e o rigor com que os subalternos executam as ordens recebidas! Como a seguir propõe a solidariedade dos membros do corpo, metáfora da velha tradição romana, desde que o cônsul Menénio Agripa a utilizara para convencer os plebeus a voltar à cidade, no longínquo ano de 503 a. C. Utilizara-a, também, por sua vez, o apóstolo Paulo numa das suas cartas.

Este capítulo sabe-nos a pouco. Esperávamos, como o título prometia, uma visão da génese da cristianização na sua globalidade e da forma como se institucionalizou na Lusitânia romana quando, afinal, a Autora apenas se fica por alguns dos condicionamentos ou factores que a possibilitaram: os contactos com África, as ligações comerciais e o exército.

O capítulo III é, a nosso ver, o melhor deste trabalho. Versa, com algum à-vontade, as questões entre a ortodoxia e a heterodoxia na Lusitânia, desde as origens do cristianismo até ao século $\mathrm{V}$, embora apareçam relativamente desligadas do seu contexto global. A exposição no que diz respeito aos problemas do arianismo e do priscilianismo é ciara. Mas também aqui se esperava alguma novidade de interpretação. Sobre o arianismo a própria Autora afirma nada mais se saber além do que, há uns quarenta anos (1969) nos trouxe (e nós acrescentamos, "com muita frescura e profundidade"), a tese de A. Montes Moreira, defendida em Teologia, na Universidade de Lovaina. Quanto ao movimento de Prisciliano, julgamos não poder concluir-se que se tratava apenas de "um conflito de interesses e rivalidades" (p. 150), pois como mais adiante é dito «há tentativa de instituir uma hierarquia paralela, tendo como consequência uma usurpação de funções" (pp. 160-161). $\mathrm{E}$ nas páginas anteriores havia discutido argumentos que provam que 0 movimento rigorista, se não era de aberta oposição dogmática, atingia aspectos morais, disciplinares e institucionais que fundamentaram, no seu tempo, a sua condenação como heresia.

Haveria que clarificar melhor a função episcopal quando, a propósito de Prisciliano, citando o c. VI do concílio de Saragoça (379 ou 380), se fala de duas hierarquias: "itinerante" e "estabelecida» (p. 139). É, por outro lado, de corrigir a afirmação, na página seguinte, de que as mulheres que seguem a vida ascética devem receber o véu aos quarenta anos: o texto não diz aos quarenta, mas após os quarenta (nisi quadraginta annorum probata aetate). 
Também não se percebe o que a Autora quer dizer na p. 161: «Esta mentalidade [heterodoxia, equivalente de pecado e de barbaries demoníaca] perdurou até aos finais do século $\mathrm{VI}$, altura em que era o (sic) bispo de Roma Gregório Magno, que juntamente com S. Patrício foram os primeiros a deixarem alguns aspectos mais radicais da cultura clássica, nomeadamente na relação com os germanos (sic)". Além da redacção obscura da frase, junta-se S. Patrício (séc. V) com Gregório Magno (590-604) numa não clarificada atitude face à cultura clássica.

Há em todo este capítulo algumas passagens e expressões que mereciam ter sido explicitadas como "a corrente ariana homeana" (p. 121) ou "o ritual do lucernarium" (p. 143). Por outro lado, ainda, é duvidoso continuar a atribuir, sem prova, a origem hispânica ao papa Dâmaso (366-384), como se afirma na página 115 . O recente e bem informado Dizionario Storico del Papato, dir. de Ph. Levillain, Milano, Bompiani, 1996, v. I, p. 483, diz, textualmente: nato in luogo e data sconosciuti.

Num juízo global diríamos que, apesar dos limites que acabamos de referir, a tese da Doutora Maria da Luz Huffstot é um trabaiho meritório enquanto abordagem de narrativa histórica, embora denuncie falta de instrumentos adequados da sua Autora para análises mais profundas e inovadoras, nos níveis institucional e doutrinal.

O livro é, porém, uma obra formalmente muito descuidada, cheia de erros de ortografia e sintaxe, que tornam a leitura irritante e desanimadora. Os vocábulos latinos quase sempre sofrem tratos de polé: o plural de passio é passiones, e é um erro dizer "as passio" (por ex., pp. 158 e 159); o plural de latifundium é latifundia (p. 159); didaskalos tem como plural didaskaloi (p. 139); escreve-se dioecesis e não diocesis, rusticitas" e não rusticicus (p. 161), etc.

São demasiados os acentos trocados, os erros ortográficos e de sintaxe: demos só dois ou três exemplos, dos muitos que enxameiam por quase todas as páginas: escreve-se criação e não "creação" (p.126); engendrado e não «ingendrado» (ibidem); salvífica e não "salvítica», (p.105); abside e não «ápside» (p. 148); Epifania e não "Epifânia" (p. 136); Estilicão e não "Estilição"; Pirenéus e não "Pirinéus" (p. 133); Mediterrâneo e não “Mediterrânio" (p. 161); perseverar e não "preservar» (no caso concreto da p. 137, n. 520). Há, igualmente, graves erros de sintaxe: «Também não estiveram presentes nenhum bispo»! (p. 133) ou "na qual procura-se apoiar para» (p. 136) e ainda "tem a haver com a reutilização", por "tem a ver com a reutilização" (p. 148). E muitos, muitos outros! Demasiados! Que teriam sido evitados com uma cuidadosa revisão do texto final. 
O que significa dizer que "o concílio teve a presença de cerca de doze bispos", quando logo a seguir se diz "os doze bispos presentes" (p. 133)? Porque é que o imperador é chamado "Valente» e poucas linhas depois o mesmo é dito "Valêncio"? (p. 121). Porquê chamar a outro imperador "Honorius" e não "Honório» (p. 124)?

Uma obra como esta, devia primar pelo rigor dos conceitos e, por isso, não pode confundir "laico» e «leigo", como acontece na página 139. Embora seja uma observação menor, julgo que tem alguma pertinência observar que em português o "pai dos monges" (Antonius), é denominado entre nós de "S. Antão" e não "S. António" (pp. 144 e 145), forma que se reserva para o santo franciscano, nascido em Lisboa, no final do século XII.

Por tudo quanto ficou dito, embora se louve o esforço da Autora em escrever, como sua tese de doutoramento em História, acerca de uma temática tão pertinente e onde continua a ser necessário muito debate e aprofundamento, só poderemos recomendar aos estudiosos da história do cristianismo antigo (e particularmente ao público académico, em formação) o livro editado, depois de uma séria revisão.

\section{Armando Martins}

ANN WARD, Herodotus and the Philosophy of Empire. Waco, Baylor University Press, 2008, 248 pp. ISBN 978-1-60258-007-7.

A recente publicação pela Baylor University Press da tese de doutoramento apresentada por Ann Ward, à Universidade de Forham, em Nova lorque, em Dezembro de 2001, sob o titulo de Philosophy and Empire. Herodotus and the Best Regime, afigura-se como um importante contributo para o estudo da filosofia politica que estruturou 0 pensamento de Heródoto ao longo das Histórias.

Através de uma análise perspicaz do texto e do confronto com as ideias de Tucídides, a A. concentra a sua atenção nos diferentes regimes políticos que governam Egípcios, Citas, Espartanos e Atenienses, ignorando a questão temporal, na sua busca do melhor regime para governar o homem, para concluir finalmente que a democracia que governa Atenas é, de todos, o melhor. No entanto, o próprio Heródoto está já muito consciente dos perigos que o imperialismo representa para a democracia. O imperialismo persa e os inícios do ateniense transformam-se assim no epicentro da obra de Heródoto, que pressagia assim a de Tucídides. 